\title{
Effects of Auto Exhaust Emission on Germination and Certain Seedling Growth Parameter of Sesbania grandiflora (L.) Poiret (hummingbird tree)
}

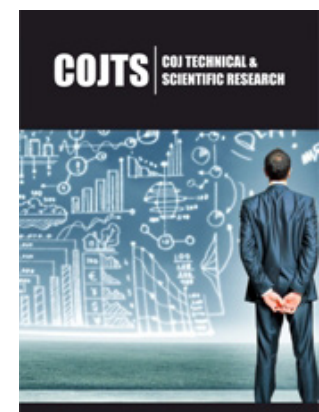

*Corresponding author: Muhammad Shafiq, Department of Botany, University of Karachi, Karachi, 75270, Pakistan, Email: shafiqeco@yahoo.com

\section{Submission: 臹 March 13, 2019}

Published: 制April 16, 2019

Volume 6 - Issue 1

How to cite this article: Shafiq M, Shahid H, Iqbal MZ, Kabir M and Farooqi ZR. Effects of auto exhaust emission on germination and seedling growth parameters of Sesbania grandiflora L. Poiret (humingbird tree). COJTS.00524.2019.

Copyright@ Muhammad Shafiq, This article is distributed under the terms of the Creative Commons Attribution 4.0 International License, which permits unrestricted use and redistribution provided that the original author and source are credited.

\begin{abstract}
The discharge of toxic pollutants from automobile exhaust emission are a dominant feature of urban environments pollution problems and represents detrimental effects on urban vegetation. The different effects of automobile exhaust emission on the seed germination and early seedling growth performance of Sesbania grandiflora (L.) Poiret was recorded. The pollutants from the auto emission showed negative effects on seedling height, leaf area, total plant fresh weight, total plant dry weight, root dry weight, stem dry weight, leaf dry weight, root/shoot ratio for fresh weight and root/shoot ratio for dry weight of Sesbania grandiflora. Auto emission showed significantly $(\mathrm{p}<0.05)$ toxic effects on seedling growth of Sesbania grandiflora growing in polluted sites (Tariq Road, Bahadurabad, Khalid Bin Waleed Road, Gulshan-e-Iqbal Gulshan-e-Iqbal) of city as compared to Karachi University Campus (Cleaner site).
\end{abstract}

The seeds of Sesbania grandiflora collected from the Karachi University campus, which is consider as control site showed better percentage of seed germination and seedling growth as compared to the seeds of the same species collected from the different polluted areas of the city. A high percentage of decrease in seed germination was found for the seeds collected from the Tariq Road, followed by Bahadurabad, Khalid Bin Waleed Road and Gulshan-e-Iqbal Gulshan-e-Iqbal as compared to control. Seedling length was also highly decreased for seeds of same species collected from Tariq Road (5.73a \pm 0.53 ) as compared to control $(21.93 \mathrm{c} \pm 1.07)$. High percentage of decrease in seedling dry weight was found for seeds of same species collected from Tariq Road, Bahadurabad, Khalid Bin Waleed Road, and Gulshan-e-Iqbal as compared to control. Root growth of Sesbania grandiflora was significantly decreased in the polluted seedlings as compared to control. According to the tolerance test it was observed that the seedling growth of Sesbania grandiflora showed lowest percentage of tolerance in samples collected from Tariq Road, followed by Bahadurabad, Khalid Bin Waleed Road and Gulshan-e-Iqbal Gulshan-e-Iqbal as compared to University Campus.

Keywords: Auto exhaust emission; Pollution; Roadside tree; Seedling growth; Urban site

\section{Introduction}

The discharge of pollutants from the faulty automobile results due to incomplete combustion of burning of gasoline, fuel. These pollutants in combinations cause greater or synergistic effects to plants. The common ingredients of vehicular pollution are nitrogen oxides, carbon monoxide, carbon dioxide, sulfur dioxide, ozone formation, hydrocarbon, heavy metals such as lead, cadmium, zinc, copper and particulate matter. These fueled vehicles plying on the busy roads of the city are responsible for generation of a wide range of pollutants, with concentrations and relative proportions of pollutants depending on vehicle technology and operating conditions [1] and accounts for $60-70 \%$ of the pollution found in the environment [2] and unwanted smoke [3].

The trees in cities faces an exceptionally stressful growing environment such as vehicular pollution suppresses the performance of plant growth [4-9]. The pollutants emitted from the auto exhaust affect the germination ability of seeds [10-12]. The seeds of Dalbergia sissoo Roxb collected from different polluted areas of the city showed significant reduction in germination as compared to seeds collected from the less polluted areas [11]. The seeds of Cassia surattensis Burm F., Leucaena leucocephala (Lam.) de-Wit and Parkinsonia aculeata L., collected from the polluted areas showed significant reduction in germination as compared 
to control [13]. The automobile activities have increased the level of metals in the environment of the major cities of the world and produced ill effects on plant growth [14-22].

Sesbania grandiflora (L.) Poiret syn. Aeschynomene grandiflora) or hummingbird tree is a small tree in genus Sesbania. It belongs to family Fabaceae. It is a fast-growing tree with a typical height between 3 and $5 \mathrm{~m}$. The leaves are regular and rounded and the flowers are white and large. The fruits look like flat, long and thin green beans. The tree thrives full exposure to sunshine and is extremely frost sensitive. It is believed to have originated either in India or Southeast Asia and grows primarily in hot and humid tropical areas of world. The sensitivity of seeds to vehicular emission has raised question about the potential impact of pollution on plant growth. Attention is being focused on the global environmental problems [23] affecting plant growth. Karachi is the largest industrial city of Pakistan. The number of registered vehicles could be up to 2.1 cars and 2.7 million motorcycles in 2025 [24]. A little work has been done on this aspect on street trees in the city. Therefore, the present research was carried out to investigate the effects of automobile pollutants on seed germination and seedling growth of Sesbania grandiflora, an important street tree species growing in different areas of the city of Karachi.

\section{Material and Methods}

\section{Site description}

Karachi is situated on the coast along the Arabian Sea. The climate of the city has been characterized as subtropical maritime desert [25]. According to Holdrige [26], the bio climate of Karachi, comes in the category of "Tropical desert bush formation". Average wind velocity is $12 \mathrm{MSec}^{-1}$ during June and July and $3.5 \mathrm{MSec}^{-1}$ from January to March. During the southwest monsoon season winds blow from the sea towards the coast, whereas during the northeast monsoon their direction is reversed. Therefore, pollutants are pushed inland during the southwest monsoon season and are blown out to sea during the northeast monsoons [27]. The hot and humid rainy season, which is variable, lasts from June to September. The winter season is very short lasting from middle of November to middle of February. The rest of the months constitute the summer, autumn and spring seasons. Temperature is mild with no frost. The dew formation is quite common, the relative humidity is high and the differences in day and night temperatures are great. The climatic conditions at the control site (Karachi University Campus) are not different from other sites of the city.

\section{Selection of sites}

The site in urban area is disturbed mainly due to auto vehicular activities which, includes all main traffic network (Tariq Road, Bahadurabad, Khalid Bin Waleed Road, Gulshan-e-Iqbal Gulshan-eIqbal) whereas, Karachi University is relatively a clean area. Brief description of the study area is given below:

1. Karachi University Campus: Karachi University Campus is situated at the outskirts of the city. This site is relatively free from the auto vehicular activities as compared to other sites of the city. Karachi University Campus is clean and $20 \mathrm{~km}$ away from Quaid-eAzam tomb.
2. Tariq Road: Tariq Road handles a large traffic volume, moving from south to north of the city. This site is about $3.9 \mathrm{~km}$ via Shahrah-e-Quaideen and away from the eastern site of Quaide-Azam tomb. It is located in P.E.C.H.S. (Pakistan Employees Cooperative Housing Society) having popular commercial Banks, Mall, small shopping places and restaurant. The site is extremely polluted area. The site is the most congested. The density of traffic from Khalid Bin Waleed Road, Shaheed-e-Millat Road and Shahrahe-Faisal passes through this road. The slow movement of the traffic starts building up of toxic pollutants in the area.

3. Bahadurabad: Bahadurabad is one of the neighborhoods of Gulshan Town and has multistoried buildings, apartments and shopping centers. This site is $9 \mathrm{~km}$ from the eastern site of the Quaid-e-Azam tomb and heavily influenced by traffic activities. The site is consist of different societies such as Sharfabad, Katchi Memon Cooperative Housing Society and Dhoraji.

4. Khalid Bin Waleed Road: Khalid Bin Waleed Road has multistoried buildings and many car show rooms. This site is $2.5 \mathrm{~km}$ from the eastern site of the Quaid-e-Azam tomb and heavily influenced by traffic activities and known as auto market. The Toyota Central Motor Workshop, car show rooms are situated on this road and accommodating many customers. The site is one of the neighborhoods of PECHS and Karachi Municipal Corporation sports complex.

5. Gulshan-e-Iqbal: Gulshan-e-Iqbal is located about $8 \mathrm{Km}$ North East of the Quaid-e-Azam tomb. This site is little polluted area. This place is comparatively open for the flow of traffic. However, traffic congestion in the morning and evening hours is quite high due to presence of different offices such as Civic Centers and Expo center. The site has also large residential, commercial centers, educational institutes, restaurants and hospitals. This site is one of the neighborhoods of Federal B area, Azizabad and Yasinabad.

The seeds of Sesbania grandiflora (L.) Poiret in enough quantities were randomly collected from the polluted sites (Tariq Road, Bahadurabad, Khalid Bin Waleed Road, Gulshan-e-Iqbal) of the city as well as from a comparatively clean area of the Karachi University Campus. Dry seeds of Sesbania grandiflora were rubbed by sand paper to break the seed dormancy. The samples were influenced by traffic and exposed sunlight. All the seeds were soaked in one percent bleach (NaOCl Sodium hypochlorite) solution for one minute and later wash with double distilled water to avoid any type of fungal contamination during germination. Ten seeds of each species were kept in well sterilized petri dishes (90mm diameter) on Whatman filter paper No. 42 at room temperature. Ordinary light was used as light source. There were three replicates and the experiment was completely randomized. The seed germination was regularly checked. After ten days seed germination counts. Data on seed germination (\%) root length $(\mathrm{cm})$, shoot length $(\mathrm{cm})$, seedling height $(\mathrm{cm})$, leaf area $\left(\mathrm{cm}^{2}\right)$, root fresh weight $(\mathrm{g})$, root dry weight (g), stem dry weight (g), leaf dry weight (g), total plant fresh weight (g), total plant dry weight $(\mathrm{g})$, root/shoot ratio fresh weight and root/shoot ratio dry weight was recorded. Each individual seedling was an observation. The different seedling parameters were measured, and their oven dry weights were obtained. The 
fresh weight of root, stem and leaves were determined separately, placed the separated parts of the plant in marked enveloped paper and finally kept in oven at $80{ }^{\circ} \mathrm{C}$ for 24 hours to obtain dry weight.

Root/shoot ratio and leaf area were determined as follows.

For dry weight:

Root/shoot ratio = Root dry weight/shoot dry weight

For fresh weight:

Root $/$ shoot ratio = Root fresh weight $/$ shoot dry weight

Leaf area:

Leaf area $=$ Leaf length $\mathrm{x}$ Leaf breadth X $2 / 3$

An index of tolerance was determined by the following formula:

Mean root length of polluted area seeds/Mean root length of campus seeds X100

The data collected for various growth parameters was statistically analyzed on the personnel computer using software packages SPSS version 13.0. The data was calculated by one-way analysis of variance techniques (ANOVA) and Duncan's Multiple Range Test (D.M.R.T.) techniques.

\section{Result}

The effect of automobile pollutants on seed germination and seedling growth of Sesbania grandiflora collected from the polluted and less polluted areas are summarized. Seeds of Sesbania grandiflora collected from the polluted areas viz. Tariq Road, Bahadurabad, Khalid Bin Waleed Road, Gulshan-e-Iqbal showed low percentage of germination, root, shoot, seedling length, leaf area, fresh and dry seedling weight as compared to seeds from the clean area (Figure 1-4). Germination of Sesbania grandiflora seeds showed better percentage of germination in samples collected from University campus as compared to Gulshan-eIqbal, Khalid Bin Waleed Road, Bahadurabad and Tariq Road. It was observed that, the automobile emission showed significantly $(\mathrm{p}<0.05)$ effects on seed germination and seedling growth of Sesbania grandiflora. Germination of Sesbania grandiflora seeds was significantly $(\mathrm{p}<0.05)$ affected in seeds collected from Tariq Road, Bahadurabad, Khalid Bin Waleed Road, and Gulshan-e-Iqbal as compared to control (Karachi University campus). Germination of Sesbania grandiflora seeds showed better percentage of germination in samples collected from University campus $(76.75 \%)$ as compared to Gulshan-eIqbal (73.25\%), Khalid Bin Waleed Road (70.00\%), Bahadurabad (63.25\%) and Tariq Road (46.75 $\%)$. The effect of vehicular emission on root length of Sesbania grandiflora was also greatly found in sample collected from Tariq Road $(3.66 \mathrm{~cm})$, Bahadurabad $(8.50 \mathrm{~cm})$, Khalid Bin Waleed Road $(7.43 \mathrm{~cm})$ and Gulshan-e-Iqbal $(11.20 \mathrm{~cm})$ as compared to campus $(15.73 \mathrm{~cm})$. Similarly, shoot length of Sesbania grandiflora was also greatly affected in sample collected from Tariq Road $(2.06 \mathrm{~cm})$, Bahadurabad $(4.06 \mathrm{~cm})$, Khalid Bin Waleed Road $(5.40 \mathrm{~cm})$ and Gulshan-e-Iqbal $(4.43 \mathrm{~cm})$ as compared to campus $(6.20 \mathrm{~cm})$.

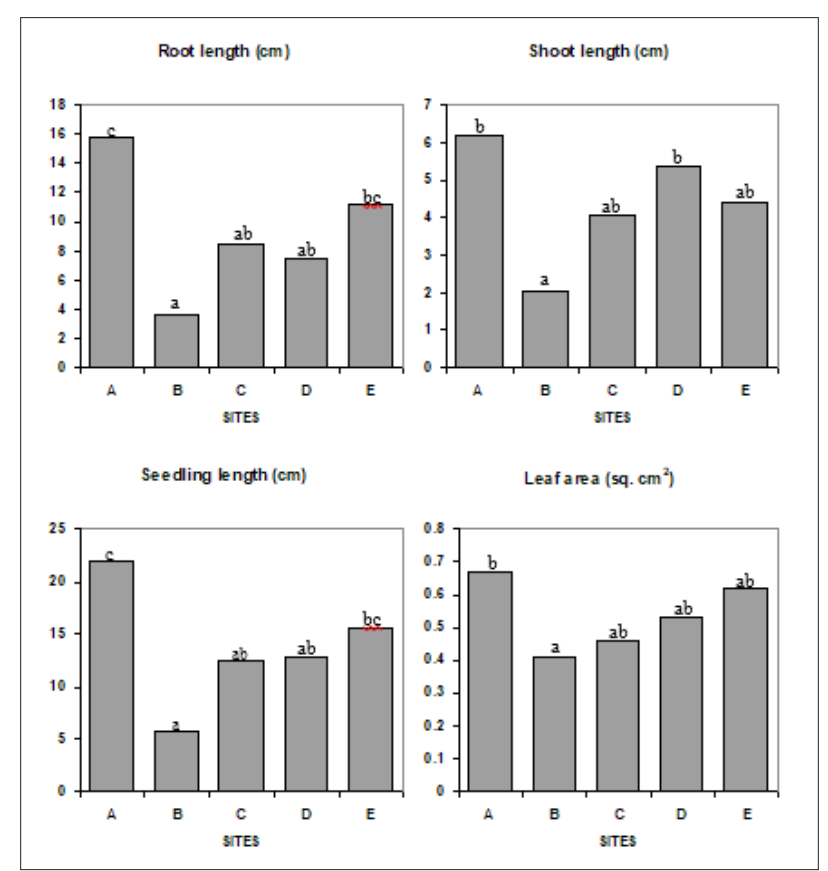

Figure 1: Effects of auto emission on root, shoot, seedling length $(\mathrm{cm})$ and leaf area (sq. $\mathrm{cm} 2)$ of Sesbania grandiflora (L.) Poiret as compared to control. Statistical significance determined by analysis of variance. Numbers followed by the same letters in the same bar not significantly different $(\mathrm{p}<0.05)$ according to Duncan's multiple range tests.

SITES: A=Karachi University campus, B=Tariq Road, C=Bahadurabad, D=Khalid Bin Waleed Road, E=Gulshane-Iqbal. 


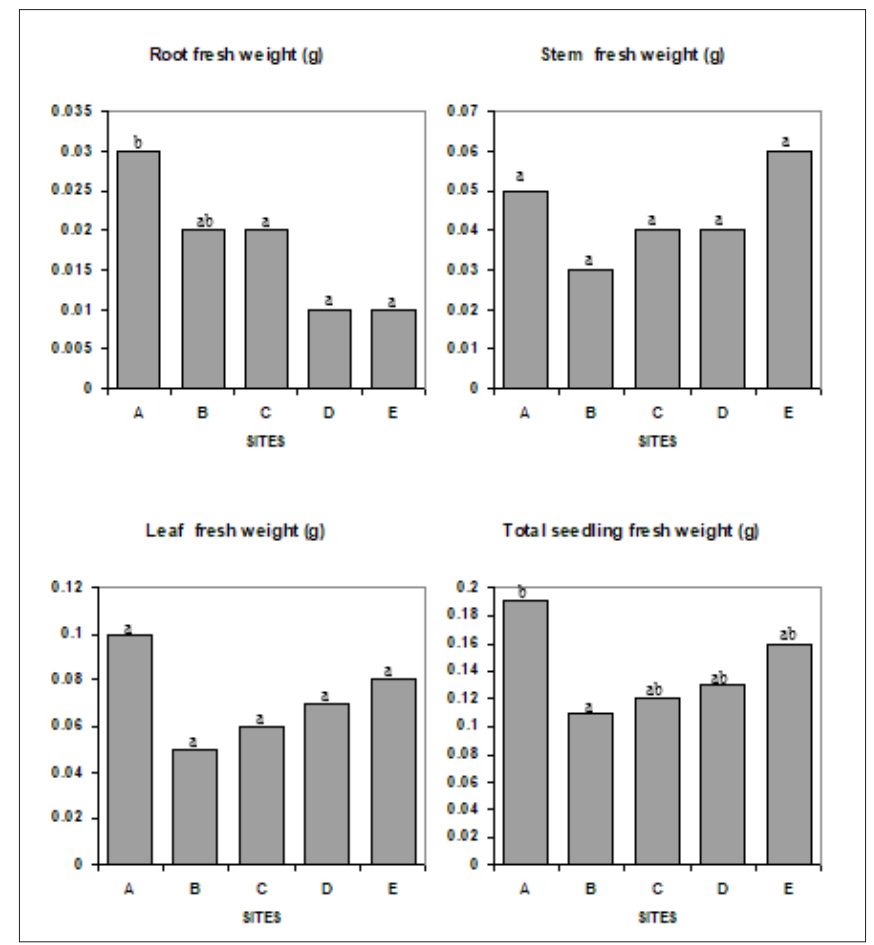

Figure 2: Effects of auto emission on root, shoot, seedling length $(\mathrm{cm})$ and leaf area (sq. $\mathrm{cm} 2)$ of Sesbania grandiflora (L.) Poiret as compared to control. Statistical significance determined by analysis of variance. Numbers followed by the same letters in the same bar not significantly different $(\mathrm{p}<0.05)$ according to Duncan's multiple range tests.

SITES: A=Karachi University campus, B=Tariq Road, C=Bahadurabad, D=Khalid Bin Waleed Road, E=Gulshane-Iqbal.

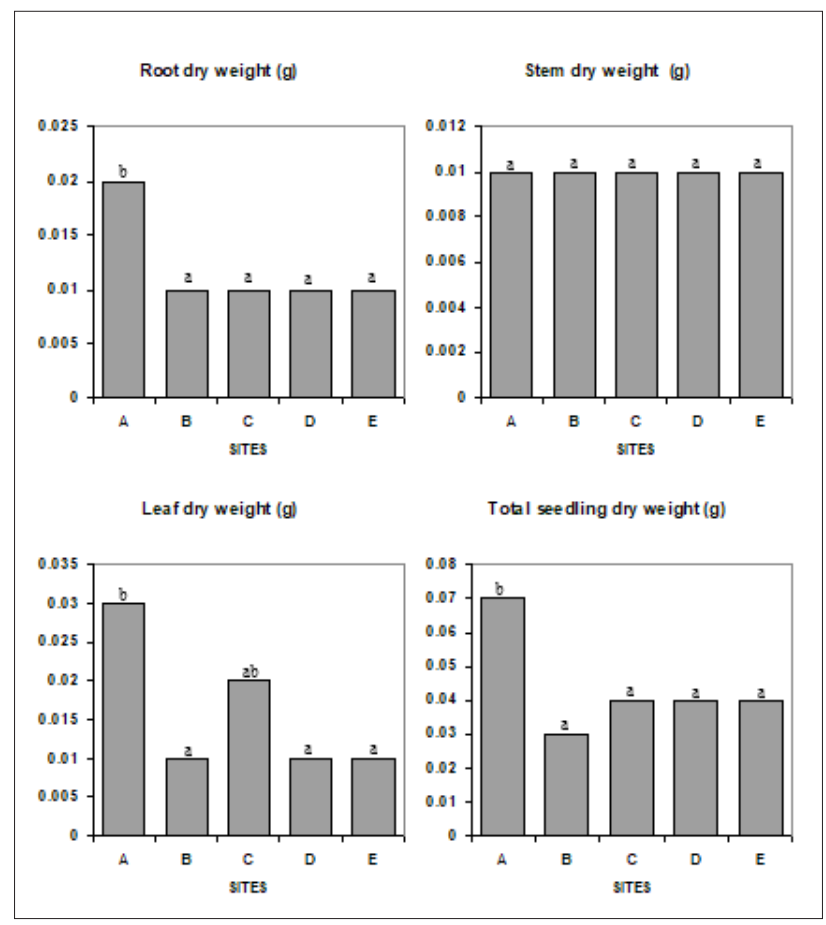

Figure 3: Effects of auto emission on root, stem, leaf and total seedling dry weight (g) of Sesbania grandiflora (L.) Poiret as compared to control. Statistical significance determined by analysis of variance. Numbers followed by the same letters in the same bar not significantly different $(p<0.05)$ according to Duncan's multiple range tests.

SITES: A=Karachi University campus, B=Tariq Road, C=Bahadurabad, D=Khalid Bin Waleed Road, E=Gulshane-Iqbal. 


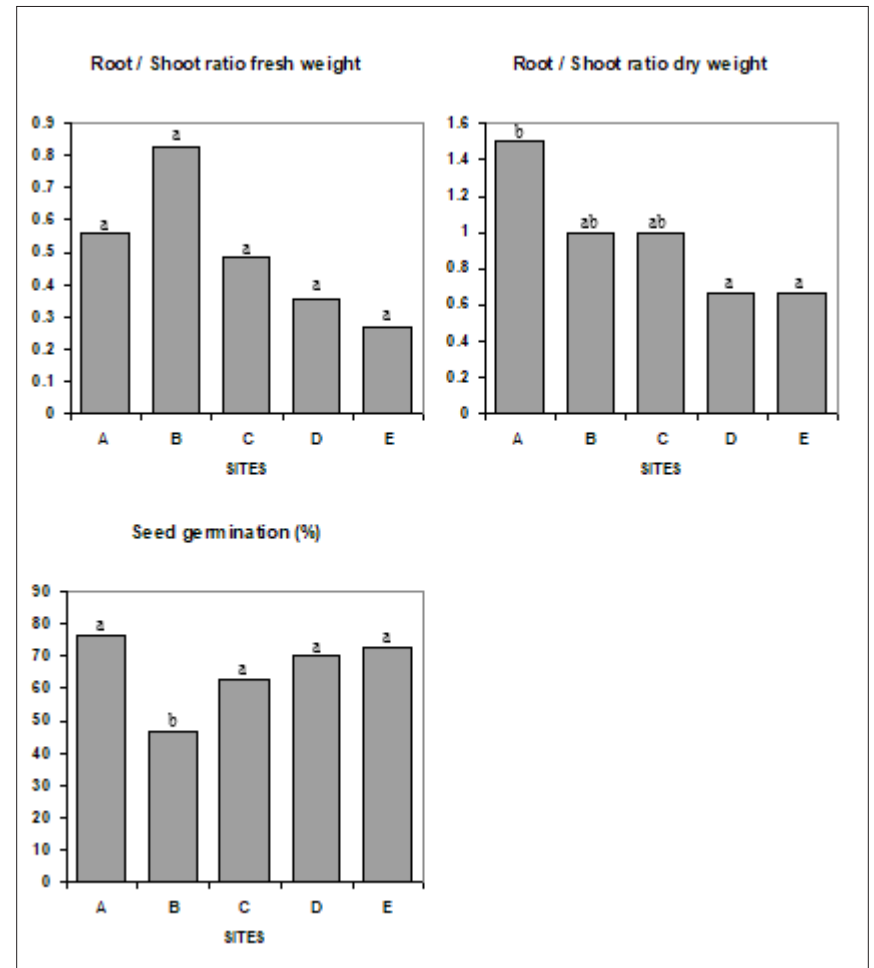

Figure 4: Effects of auto emission on root/shoot ratio fresh weight, root/shoot ratio dry weight and seed germination (\%) and total seedling dry weight (g) of Sesbania grandiflora (L.) Poiret as compared to control. Statistical significance determined by analysis of variance. Numbers followed by the same letters in the same bar not significantly different $(\mathrm{p}<0.05)$ according to Duncan's multiple range tests.

SITES: A=Karachi University campus, B=Tariq Road, C=Bahadurabad, D=Khalid Bin Waleed Road, E=Gulshane-Iqbal.

Automobile emission showed significantly $(p<0.05)$ toxic effects on seedling length of Sesbania grandiflora. Germination of Sesbania grandiflora seeds was significantly $(\mathrm{p}<0.05)$ affected in seeds collected from Tariq Road $(5.73 \mathrm{~cm})$, Bahadurabad $(12.56 \mathrm{~cm})$, Khalid Bin Waleed Road $(12.83 \mathrm{~cm})$ and Gulshan-e-Iqbal $(15.3 \mathrm{~cm})$ as compared to control $(21.93 \mathrm{~cm})$. The leaf growth of Sesbania grandiflora was also greatly affected in sample collected from Tariq Road $\left(0.41 \mathrm{~cm}^{2}\right)$, Bahadurabad $\left(0.46 \mathrm{~cm}^{2}\right)$, Khalid Bin Waleed Road $\left(0.53 \mathrm{~cm}^{2}\right)$ and Gulshan-e-Iqbal $\left(0.62 \mathrm{~cm}^{2}\right)$ as compared to campus $\left(0.41 \mathrm{~cm}^{2}\right)$. Automobile pollutants significantly affected the biomass production of Sesbania grandiflora seedlings raised from the seeds collected from the different sites of the city showed low percentage of root, stem, total seedling fresh and dry seedling weight as compared to seeds from the clean area. Root fresh weight of Sesbania grandiflora showed a significant decrease in samples collected from Tariq Road (0.02g), Bahadurabad (0.02g), Khalid Bin Waleed Road (0.01g) and Gulshan-e-Iqbal (0.01g) as compared to campus (0.03g).

Stem and leaf fresh weight of Sesbania grandiflora showed nonsignificant decrease in samples collected from Tariq Road, Bahadurabad, Khalid Bin Waleed Road and Gulshan-e-Iqbal as compared to campus area. total seedling fresh weight of Sesbania grandiflora also showed significant decrease in samples collected from Tariq Road (0.11g), Bahadurabad (0.12g), Khalid Bin Waleed Road $(0.13 \mathrm{~g})$ and Gulshan-e-Iqbal $(0.16 \mathrm{~g})$ as compared to campus (0.18g). Root dry weight of Sesbania grandiflora showed significant decrease in samples collected from Tariq Road (0.01g), Bahadurabad (0.01g), Khalid Bin Waleed Road (0.01g) and Gulshan-e-Iqbal $(0.01 \mathrm{~g})$ as compared to campus $(0.02 \mathrm{~g})$. The pollutants derived from automobile did not produce any significant effect on stem dry weight of Sesbania grandiflora. A significant decrease in leaf dry weight observed in samples collected from Tariq Road (0.01g), Bahadurabad (0.02g), Khalid Bin Waleed Road (0.01g), and Gulshane-Iqbal $(0.01 \mathrm{~g})$ as compared to campus $(0.03 \mathrm{~g})$. Total seedling dry weight of Sesbania grandiflora was also significantly decreased in samples collected from Tariq Road (0.11g), Bahadurabad (0.12g), Khalid Bin Waleed Road (0.13g) and Gulshan-e-Iqbal (0.16g) as compared to campus $(0.19 \mathrm{~g})$. The effects of auto exhaust emission on root/shoot ratio fresh weight and root/shoot ratio dry weight of Sesbania grandiflora was non significantly affected in sample collected from polluted sites as compared to campus. Whereas, a significant $(\mathrm{p}<0.05)$ effects of auto emission on root/shoot ratio dry weight of Sesbania grandiflora was found in sample collected from Tariq Road followed by Bahadurabad, Khalid Bin Waleed Road and Gulshan-e-Iqbal as compared to control site. According to the tolerance test seeds of Sesbania grandiflora collected from the polluted area of the city showed low percentage of tolerance in seedling growth as compared to seeds of Sesbania grandiflora collected from the less polluted areas (Figure 5). Seedling growth of Sesbania grandiflora showed the lowest percentage of tolerance 
in samples collected from Tariq Road (23.26\%) as compared to control. Similarly, seedling growth of Sesbania grandiflora showed better percentage of tolerance in samples collected from Khalid Bin Waleed Road (54.03\%) and Bahadurabad (47.23\%) as compared to Campus. Auto exhaust emission showed toxic effects on seedling vigor index of Sesbania grandiflora (Figure 6). Seedling vigor index of Sesbania grandiflora was highly affected in seeds collected from Tariq Road (270), Bahadurabad (791), Khalid Bin Waleed Road (890) and Gulshan-e-Iqbal (1199.60) as compared to control (1683.12).

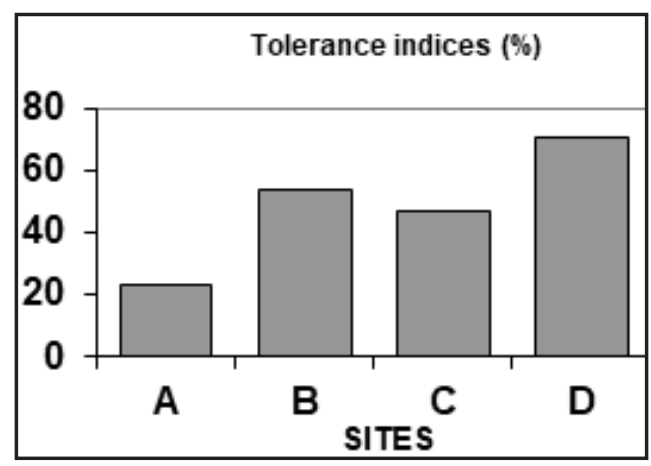

Figure 5: Percentage of tolerance indices in seedling growth performance of Sesbania grandiflora (L.) Poiret raised from polluted areas seed as compared to control.

SITES: A=Tariq Road, B=Bahadurabad, C=Khalid Bin Waleed Road, D=Gulshan-e-Iqbal.

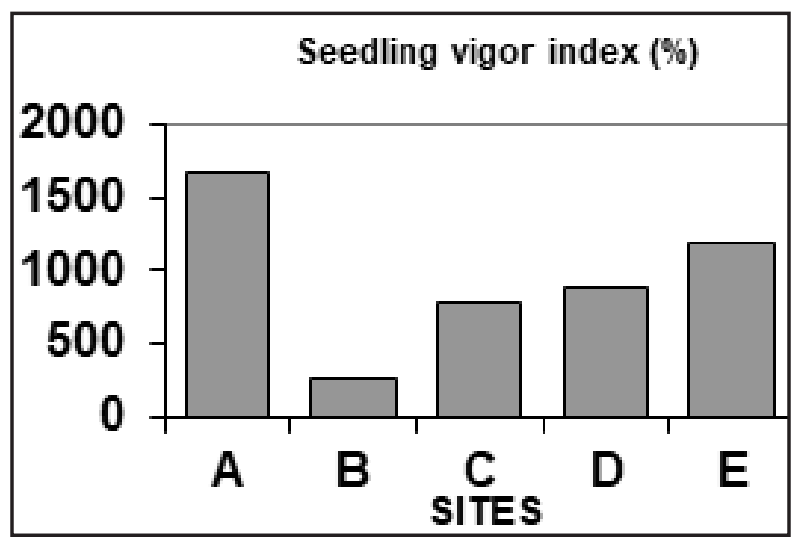

Figure 6: Percentage of seedling vigor index (\%) of Sesbania grandiflora (L.) Poiret raised from polluted areas seed as compared to control.

A=Karachi University campus, B=Tariq Road, C=Bahadurabad, D=Khalid Bin Waleed Road, E=Gulshan-e-Iqbal.

\section{Discussion}

Karachi is the largest and densely populated city of Pakistan, where automobiles activities are increasing day-by-day. Roadside trees in the city are coming under pressure due to vehicular activities (Guderian, 1977; Jim, 1998). Literature is available on the effect of auto exhaust emission impact on germination and growth of roadside plants. In present study, the negative effects of automobile exhaust emission on germination and growth of Sesbania grandiflora observed. In present studies the seeds of Sesbania grandiflora (L.) Poiret, collected from different polluted areas of the city decreased the germination percentage and seedling growth characteristics as compared to seeds collected from the less polluted area. Sesbania grandiflora growing in different sites of the city are under pressure of environmental stress due to addition of toxic pollutants derived from the automobile. The presence of the toxic pollutants in the immediate environment can directly affect the plant ability to produce healthy seeds. MacLean \& Schneider [28] have reported a decrease in fruit production of beans and tobacco cultivars due to oxidants.

The results of the present investigations are testifying this grave situation facing for roadside plants growing at the polluted sites of the city. The reduction in seed germination of Sesbania grandiflora seeds collected from the polluted areas of Tariq Road, Bahadurabad, Khalid Bin Waleed Road, and Gulshan-e-Iqbal as compared to seeds of Sesbania grandiflora collected from Karachi University campus agrees with the findings of Iqbal \& Siddiqui [29]. They have found reduction in seed germination of Pongamia pinnata (L.) Merrill collected from other parts of the polluted areas of Karachi, city. In another study, the seeds of Dalbergia sissoo Roxb. and Albizia lebbeck (L.) Bth collected from other different areas of the Karachi, 
city showed significant reduction in germination as compared to clean area $[8,11,12]$. The other reason of high percentage of reduction in seed germination of Sesbania grandiflora collected from polluted sites of the city could be due to structure of the pod. The seedling growth of Sesbania grandiflora raised from the seed collected from different sites of the city was found low as compared to seeds collected from the campus areas. Significant $(\mathrm{p}<0.05)$ reduction in seed seedling length was observed in seeds of Sesbania grandiflora collected from Tariq Road as compared to Bahadurabad, Khalid Bin Waleed Road, Gulshan-e-Iqbal and Karachi University campus (Control). The possible reason for reduction in seedling growth of Sesbania grandiflora could be due to the development of unhealthy seeds produced by trees growing along the main road of the city. The other reason of inhibitory factor in controlling the germination and seedling growth of Sesbania grandiflora can be attributed to the physical constraints induced by dust and diesel fuel particles available in the nearby soil and absorbed by the seed due to automobile activities. Diesel fuel would cause a film of oil to form around the seed, which would act as a physical barrier, preventing or reducing both water and oxygen transfer to the seed. This physical impedance was shown to delay seed emergence and therefore could be an additional factor in the overall inhibitory effect of diesel fuel contamination on germination and growth of plants [30].

In the present study, the seeds of Sesbania grandiflora collected from different polluted and less polluted sites of the city behaved differently to produce seedling fresh and dry weight. The pollutant emitted from the auto exhaust has greatly influenced the seedling dry weight capability of roadside plants. The seedling dry weight was reduced in the polluted seedlings as compared to control. The yield of seeds and fruits of Guiacum officinale \& Azadirachta indica was lessened at polluted sites [31]. In our previous investigation it was observed that biomass production of some roadside's trees was more sensitive to air pollutant particularly at M.A. Jinnah road as compared to other less polluted areas of the city [32]. In auto vehicular pollution, some hidden or physiological changes or metabolic disorders of plants take place which affect the reproductive capacity of plants and enforce plants to produced low viability of seeds. Low percentage of seedling dry weight of Sesbania grandiflora has proved the loosing viability of the seeds.

The root-shoot ratio is usually given as the ratio of the weight of the roots to the weight of the top of a plant [33]. A cultural practice that brings about a reduction in the root-shoot ratio of a tree is commonly thought to be detrimental for the well-being of the tree. That is, proportionately more top than root growth is thought not to be in the best interests of a tree. However, any factor which improves growing conditions, such as favorable weather, fertilization, irrigation, aeration, or pest control, results in a reduced root-shoot ratio (weight). The root/shoot ratio responded differently in the seeds of Sesbania grandiflora collected from different polluted and less polluted sites of the city. The tolerance of plants to pollutants enables them to produce a greater number of viable seeds [34]. Furthermore, decrease in seedling growth of
Sesbania grandiflora tolerance can be attributed to the presence of toxic pollutants in the environment of Tariq Road, Bahadurabad, Khalid Bin Waleed Road, Gulshan-e-Iqbal and control sites from where the seeds were collected. This is also demonstrated that the seeds of Sesbania grandiflora collected from Tariq Road less tolerant to auto exhaust emission than the seeds of same species collected from the Bahadurabad, Khalid Bin Waleed, and Gulshan-eIqbal as compared to control site (University Campus), respectively [35]. The degree of different percentage of tolerance in seedling of Sesbania grandiflora is due to their adaptation to the different environment. This study further confirms that the seed viability of Sesbania grandiflora was more affected in seed collected from plants growing close to the roadside.

\section{Conclusion}

It is concluded, that pollutants from the automobile exhaust emission showed a powerful negative effect on seed germination and seedling growth performance of Sesbania grandiflora. The present study confirms that the seeds of Sesbania grandiflora collected from the polluted areas of the city showed some potential of adaptability to some extent. It is evident from the data that seedling length decreased in the seedlings of Sesbania grandiflora raised from the seeds collected from the polluted areas [36]. The bounded relationships between decreases in seedling length root and biomass production, can be understood from the synchronized decrease in fresh weight and dry weight in response to shoot and root length. As we are aware that that once the contamination of pollutant established in environment, it is difficult to eradicate completely [37]. Although this has been an intense area of research to be need for further studies. Strong dedication from all civic agencies is required to preserve this economic an important arid street tree species Sesbania grandiflora from the extinction in future at least growing at Tariq road site.

\section{References}

1. Colvile RN, Hutchinson EJ, Mindell JS, Warren RF (2001) The transport sector as a source of air pollution. Atmospheric Environment 35(9): 1537-1565.

2. Dwivedi AK, Tripathi BD, Shashi (2008) Effect of ambient air sulfur dioxide on sulphate accumulation in plants. Journal of Environmental Biology 29(3): 377-379.

3. Harish M (2012) Air pollution by automobiles of existing situation in Mysore city. International Journal of Advances in Pharmacy, Biology and Chemistry 1(2): 227-233.

4. Gilbertson P, Bradshaw AD (1985) Tree survival in cities; The extent and nature of the problem. Arboricultural Journal 9(2): 131-142.

5. Jehan S, Iqbal MZ (1992) Morphological and anatomical studies of leaves of different plants affected by motor vehicular exhaust. Med J Islamic World Acad Sci 5(1): 21-23.

6. Sawidis T, Marnasidis A, Zachariadis GA, Stratis JA (1995) A study of air pollution with heavy metals in Thessaloniki city (Greece) using trees as biological indicators. Archives of Environmental Contamination and Toxicology 28(1): 118-124.

7. Jim CY (1998) Pressure on urban trees in Hong Kong: Pervasive problem and possible amelioration. Arboricultural Journal 22(1): 37-60. 
8. Iqbal MZ, Shafiq M, Rizvi SWA (1997) Effect of traffic exhaust on roadside trees during different seasons. Polish Journal of Environmental Studies 6(5): 55-59.

9. Bell JN, Honour SL, Power SA (2011) Effects of vehicle exhaust emissions on urban wild species. Environ Pollut 159(8-9): 1984-1990.

10. Guderian R (1977) Air pollution. Springer-Verlag Berlin-Heideberg, Federal Republic of Germany, Europe, p. 127.

11. Mehmood MT, Iqbal MZ (1989) Impact of vehicular emission on seed germination of some roadside trees. Pakistan Journal of Scientific and Industrial Research 32: 752-753.

12. Qadir N, Iqbal MZ (1991) Growth of some plants raised from polluted and unpolluted seeds. International Journal Environmental Studies 39(1-2): 95-99.

13. Siddiqui AD, Iqbal MZ (1994) Growth reduction in some roadside plants. Ekologia (Bratislava), Slovakia, 13: 155-159.

14. Abdullah CM, Iqbal MZ (1991) Response of automobile, stone and cement particulate matters on stomatal clogging of plants. Geobios 18: 196-202.

15. Al Saleh IA, Taylor A (1994) Lead concentration in the atmosphere and soil of Riyadh, Saudi Arabia. Science of the Total Environment 141(1-3) 261-267.

16. Alfani A, Maisto G, Iovieno P, Rutigliano FA, Bartoli G (1996) Leaf contamination by atmospheric pollutants as assessed by elemental analysis of leaf tissue, leaf surface deposit and soil. Journal of Plant Physiology 148(1-2): 243-248

17. Ara F, Iqbal MZ, Qureshi MS (1996) Determination of heavy metals contamination of trees and soils due to vehicular emission in Karachi city. Karachi University Journal of Science 24: 80-84.

18. Hussain F, Sher Z, Shah Z, Durrani MJ (1997) Effects of air borne particulate pollutants on the growth of some roadside cultivated plants. Pakistan Journal of Plant Sciences 3: 73-82.

19. Alam SP, Ahmad MS (1998) Effect of environmental pollution on the phenological behavior of Croton bonplandianum population. In abstracts on pollution, position, and prospects. Oriental College Patna, India, p. 13.

20. Aksoy A, Sahln U (1999) Elaeagnus angustifolia L as a biomonitor of heavy metal pollution. Turkish Journal of Botany 23: 83-87.

21. Aksoy A, Sahln U, Duman F (2000) Robinia psueo-acacia L as a possible biomonitor of heavy metal pollution in Kayseri. Turksih Journal of Botany 24: 279-284.

22. Shafiq M, Iqbal MZ (2003) Effects of automobile pollution on the phenology and periodicity of some roadside plants. Pak J Bot 35(5): 931-938.
23. Hassanuzzaman M, Ahmed KU, Rahmatullah NM, Akhter N, Nahar K, et al. (2010) Plant growth characters and productivity of wetland rice (Oryza sativa L) as affected by application of different manures. Emirates J Food Agric 22(1): 46-58

24.ADB-Asian Development Bank (2013) Pakistan: Karachi bus rapid transit project, Pakistan.

25. Chaudhry II (1961) The vegetation of Karachi. Vegetatio 10(3-4): 229246.

26. Holdridge RL (1947) Determination of plant formations from simple climatic data. Science 105(2727): 367-368.

27. UNEP-United Nation Environmental Programme (1992) Urban air pollution in megacities of the world. Blackwell Publishers, Oxford, UK, p. 230.

28. Maclean DC, Schneider RE (1976) Photochemical oxidants in Yonkers, New York: Effects on yield of bean and tomato. Journal of Environmental Quality 5(1): 75-78.

29. Iqbal MZ, Siddiqui AD (1996) Polish Journal of Environmental Studies 5: 67-69.

30. Adam G, Duncan H (2002) Influence of diesel fuel on seed germination. Environmental Pollution 120(2): 363-370.

31. Bhatti GH, Iqbal MZ (1988) Investigations into the effect of automobile exhausts on the phenology, periodicity and productivity of some roadside trees. Acta Societies Botanicorum Poloniac 57(3): 395-399.

32. Shafiq M, Iqbal, MZ (2005) The impact of auto emission on the biomass production of some roadside plants. International Journal of Biology and Biotechnology 2(1): 93-97.

33. Harris RW (1992) Root shoot ratios. Journal of Arboriculture 18(1): 3942.

34. Pell EJ, Puente M (1988) Impact of simulated acid rain on yield of a field grown oat crop. Environment and Experimental Botany 27(4): 403-407.

35. Mohiuddin F (2005) 3,000 Environmentally hazardous buses plying on city roads. Jang Group of Newspapers, Pakistan.

36. Shafiq M, Iqbal MZ (2012) Impact of Automobile Pollutants on Plants. LAMBERT Academic Publishing, Saarbrücken, Germany, p. 132.

37. Tripathi AK, Gautam M (2007) Biochemical parameters of plants as indicators of air pollution. Journal of Environmental Biology 28(1): 127132

For possible submissions Click below: 